Semântica e enunciação: a designação da palavra escravidão em artigos do jornal Folha da Noite do início do século $X X$

PAULA MACHADO, Carolina

de. Semântica e enunciação: a

designação da palavra escravidão em

artigos do jornal Folha da Noite do início do século $X X$. Entrepalavras, Fortaleza, v. 7, p. 175-192, jan./jun.
Semantics and enunciation: the designation of the word slavery within Folha da Noite's newspaper articles in the beginning of the 20th century.

Carolina de PAULA MACHADO (UFSCar) carolinapmac@gmail.com
Resumo: A escravidão deixou marcas que ainda não desapareceram e podem ser percebidas não apenas nos museus, em documentos, e objetos, mas também na desigualdade social que temos hoje, no racismo presente nas redes sociais, na violência de qualquer tipo, nas práticas de trabalho escravo que ainda existem, embora sejam crimes, etc. Considerando que é na e pela linguagem que essas práticas são significadas e perpetuadas, temos como objetivo, neste artigo, descrever os sentidos da palavra escravidão depois da abolição dos escravos no Brasil, no jornal "Folha da Noite", no início do século XX. Perguntar pelos sentidos é buscar observar o que designa a palavra escravidão e, assim, identificar alguns sentidos que circularam e quais eram silenciados na época da primeira República. Esta pesquisa é desenvolvida tomando por base a Semântica do Acontecimento, uma semântica enunciativa que dialoga com a Análise de Discurso materialista. Para a realização das análises, selecionamos as ocorrências da palavra escravidão nos artigos jornalísticos e observamos dois procedimentos de textualidade: a reescrituração e a articulação. As análises revelaram uma relação semântica entre 
v. 7 (1) 175-192 jan/jun 2017

escravidão e o regime republicano, sendo que a República é significada como escravatura branca. Há, também, um deslizamento de sentidos que já significa algumas práticas no trabalho legal como escravidão.

Palavras-chave: Escravidão. Semântica. Designação.

\begin{abstract}
Slavery left marks that have not yet disappeared and can be seen not only in museums, documents and objects, moreover in social inequalities that we have today, in racism among social medias, in any type of violence, in slave work practices that still exist - although they are a crime, etc. Considering that it is in and through language that those practices are signified and perpetuated, this article has the objective of describing the meanings of the word slavery after the abolition of slavery in Brazil, presented in the newspaper "Folha da Noite" in the beginning of the $20^{\text {th }}$ century. Asking for meaning is to observe what designates the word slavery thus identifying the meanings that surrounded and were silenced by the time of the First Republic in Brazil. This research development is based on the Semantics of the Events theory, an enunciatively semantics which dialogs with the Materialist Discourse Analysis theory. In regards of the analyses, the occurrences of the word slavery on the newspaper were selected and we observed through two textual procedures: rewriting and articulation. The analyses revealed a semantic relation between slavery and the republican regime - meaning The Republic as a white slavery. Moreover, there is a change of meanings signifying some practices at work as slavery.
\end{abstract}

Keywords: Slavery. Semantics. Designation.

\title{
Introdução
}

A escravidão vigorou no Brasil por vários séculos e, juridicamente, deixou de existir em 1888. Desconfiamos, justamente, dessa evidência da abolição que produz uma "falsa-aparência", como nos diz Pêcheux (1997, p.32), de "um real natural-social-histórico homogêneo coberto por uma rede de proposições lógicas(...)". É como se do dia para a noite, através de um documento, a prática escravocrata exercida durante séculos sobre mais de um milhão de pessoas ${ }^{1}$, num país de dimensões continentais, tivesse desaparecido. É inegável, entretanto, que a escravidão deixou marcas que ainda não desapareceram e podem ser percebidas não apenas nos museus, em documentos e objetos, mas também na desigualdade social que temos hoje, no racismo que circula nas redes sociais, pela violência, através de práticas de trabalho escravo que ainda existem, embora sejam crime etc, práticas que se materializam na e pela linguagem.

Levando em consideração estes aspectos, buscamos observar o modo como a escravidão se significa e é significada pelos sujeitos, já

\footnotetext{
${ }^{1}$ De acordo com o censo de 1872 , de um total de 9.930.478 pessoas que viviam no Brasil, 1.510.806 eram escravas. Disponível em: <http://oglobo.globo.com/sociedade/historia/ censo-de-1872-unico-registrar-populacao-escrava-esta-disponivel-7275328>. Acesso em: 29 jul. 2016.
} 
que a língua é a materialidade do discurso e este é a materialidade da ideologia, conforme Orlandi (1999). Desse modo, o intuito de nossa pesquisa ${ }^{2}$, ainda em desenvolvimento, é identificar quais sentidos a palavra escravidão adquire depois da sua abolição no Brasil, pelo modo como ela é designada nos textos, tomando como lugar de observação jornais impressos do início do século XX. Neste artigo, apresento as análises, e seus resultados, de artigos do jornal "Folha da Noite". Essa pesquisa é possível porque trabalhamos no quadro teórico da Semântica do Acontecimento, uma semântica de base enunciativa que dialoga com a Análise de Discurso materialista, inserindo-nos na área temática de teoria e análise linguística.

Nessa perspectiva teórica, de acordo com as reflexões de Guimarães (2002; 2007), o sentido de uma palavra é definido pelas relações que as palavras estabelecem entre si no texto. Além disso, considera-se a relação das palavras com a temporalidade do acontecimento enunciativo, isto é, com o memorável, que é o passado de enunciações recortado pelo presente do acontecimento, e com a sua futuridade, ou seja, o futuro de interpretações. Tratar o sentido na enunciação envolve também os sujeitos, constituídos enquanto tais pela historicidade, os quais enunciam afetados pelos lugares sociais de que falam. Os sentidos produzidos na enunciação revelam a maneira como os sujeitos se inscrevem/são inscritos nas práticas sociais e como a realidade vai sendo significada, e mais do que isso, dividida, partilhada, hierarquizada, por certos dizeres. Para tanto, dois procedimentos de textualidade são analisados, quais sejam, a reescrituração da palavra escravidão e a sua articulação a outras palavras, procedimentos estes que, ao realizarem a tessitura textual, vão atribuindo sentidos à palavra analisada. Selecionamos os artigos jornalísticos pelas ocorrências da palavra escravidão nos textos, realizando a busca através da própria ferramenta de pesquisa do site do jornal "Folha de São Paulo"3, que contém um arquivo do jornal "Folha da Noite", que se inicia a partir de 1921.

Assim, buscamos saber quais sentidos de escravidão circulam durante a República recém-constituída, a chamada "República Velha",

\footnotetext{
${ }^{2}$ A pesquisa apresentada em forma de artigo é parte do projeto regular FAPESP n. 2015/16397-2 "Argumentação, textualidade e designação na Semântica do Acontecimento: os sentidos nos diferentes modos de escravidão.", coordenado pela Profa. Dra. Soeli M. Schreiber da Silva, no qual sou pesquisadora associada.

3 No início dos anos 20 do século XX, surgem os jornais "Folha da Noite" e "Folha da Manhã". Logo depois, também surge o jornal "Folha da tarde". Posteriormente, esses jornais unem-se em um só jornal, a "Folha de São Paulo".
} 
v. 7 (1)

175-192 jan/jun 2017

erigida sobre a extinção da escravidão enquanto forma de trabalho que sustentou a economia do Brasil nos séculos anteriores. Sendo a linguagem, por princípio teórico, constituidora de nossa relação com o real, aquilo que uma palavra significa ou deixa de significar, por força de instituições, de instrumentos linguísticos, da mídia, etc., é determinante para as práticas na/da sociedade. Considerando, então, que "o sentido das expressões linguísticas tem a ver com os textos em que estão" (GUIMARÃES, 2011,p. 40), vamos observar os textos jornalísticos, sabendo que os jornais, nas suas mais diversas modalidades, sempre tiveram, e ainda têm, papel fundamental nas práticas sociais, no processo de subjetivação.

\section{O sentido na enunciação}

Em virtude dessa relação constitutiva da linguagem com a sociedade, da significação de uma palavra simbolizar algo do real, o que designa escravidão nos textos jornalísticos em questão possibilita que observemos os modos como a sociedade brasileira do início do século XX (ou pelo menos uma parte dela) estava lidando com a escravidão e com seus resquícios. Como o nosso objetivo é observar o que designa a escravidão, selecionamos artigos jornalísticos sobre contextos sociais brasileiros em que a palavra ocorria.

Os textos jornalísticos que analisamos até o momento 4 e que trazemos neste artigo abrangem o período de 1921 e 1923 e são apenas do jornal "Folha da Noite".

Cada texto, de nosso ponto de vista, configura-se como um acontecimento enunciativo no qual a ocorrência da palavra escravidão revela seus sentidos, constituídos a partir do lugar social de locutorjornalista. O acontecimento enunciativo é aqui compreendido como:

\footnotetext{
diferença na sua própria ordem. E o que caracteriza a diferença é que o acontecimento não é um fato no tempo. Ou seja, não é um fato novo enquanto distinto de qualquer outro ocorrido antes no tempo. O que caracteriza como diferença é que o acontecimento temporaliza. Ele não está num presente de um antes e de um depois no tempo. O acontecimento instala sua própria temporalidade: essa é a sua diferença (GUIMARÃES, 2002, p. 12).
}

4 Esta pesquisa está em desenvolvimento e faz parte do projeto regular FAPESP n. 2015/16397-2 "Argumentação, textualidade e designação na Semântica do Acontecimento: os sentidos nos diferentes modos de escravidão.", coordenado pela profa. Dra. Soeli Maria Schreiber da Silva. 
Assim, os sentidos se constituem pela temporalidade do acontecimento enunciativo que organiza um passado de enunciações no presente da enunciação, projetando um futuro de interpretação para a palavra que está sendo analisada.

Além disso, o sentido é tratado pelo conceito de designação, compreendido como "uma relação linguística de sentido enquanto exposta ao real. Deste modo esta relação linguística é uma relação tomada na história" (GUIMARÃES, 2007, p. 81). Ou seja, o presente da enunciação recorta um passado de enunciações de forma a produzir outros sentidos. Trata-se de uma relação semântica instável, ao mesmo tempo em que se ancora no já dito e no que está sendo dito.

Analisamos, então, as relações semânticas que a palavra estabelece com outras palavras no enunciado, no texto. O enunciado é, portanto, a nossa unidade de análise, sem desconsiderarmos que ele integra o sentido de um texto e sem desconsiderar que a palavra o constitui, de modo que partimos dela. Como define Guimarães (2011), "o texto é unidade de sentido que integra enunciados". Deste ponto de vista, uma palavra adquire certos sentidos ao integrar enunciados, que integram um texto.

Assim, as relações de sentidos que se estabelecem na enunciação podem atravessar os textos, não sendo estas relações feitas, necessariamente, segmento a segmento. É o que chamamos de transversalidade, isto é, a relação de sentido entre as palavras pode se dar por sobre as articulações sintáticas no texto:

\begin{abstract}
a interpretação do sentido não é o percurso que se faz na estrutura sintática de seus componentes até a sua totalidade, trata-se da consideração de atribuição de sentido que sofre os enunciados considerados na relação com o sujeito pelo acontecimento de enunciação. A interpretação semântica não se reduz à projeção de uma regra de "leitura" automática dos elementos da sintaxe. A interpretação semântica é feita de um lugar de leitor, (...). (GUIMARÃES, 2011, p.33)
\end{abstract}

Nosso olharparao texto, portanto, édirecionadoparadescrevermos como os sentidos se constituem nele, resultando na designação, e que fazem dele uma unidade e não nos limitamos às relações sintáticas. O que vamos analisar são as relações de determinação de sentido que fazem com que as palavras se integrem e formem o texto. E isso se estabelece pela presença do sujeito no texto, assim como a sua leitura é feita a partir de um lugar de leitor.

Em nossas análises, o intuito é abranger as primeiras décadas da 
v. 7 (1)

$175-192$ jan/jun 2017

República. Sendo assim, partimos dos primeiros exemplares do Jornal Folha da Noite que estão digitalizados a partir de 1921.

Nossa seleção dos textos levou em conta os contextos decisivos de ocorrência da palavra escravidão para a constituição do seu sentido, de maneira que apenas os artigos e os enunciados que traziam reescrituras ou articulações significativas em relação à palavra no conjunto dos textos e a sua história de enunciações é que foram considerados para a análise.

Partimos da ocorrência da palavra escravidão analisando o seguinte:

a. a maneira como ela é reescrita nos textos de modo que, ao ser reescrita, os sentidos vão se constituindo;

b. a sua articulação com outras palavras, que não a reescrevem, e que determinam seu sentido.

A reescrituração é o modo como, no texto, a palavra é dita novamente mas com outras palavras e nessa medida, sentidos vão sendo atribuídos a ela, remetendo ao real.

A articulação entre as palavras também é analisada. Para Dias:

(...) a articulação na língua é contraída no confronto entre uma história das enunciações da língua e uma atualidade do uso. A história das enunciações proporciona a estabilização de lugares, e esses lugares são essenciais para a configuração das unidades da língua. E qualquer expressão que viemos a proferir tem, necessariamente, de se organizar a partir desse arcabouço de lugares. A explicitação ou não da articulação entre as unidades, sofre de um lado, a coerção dos lugares sintáticos, e, de outro, as necessidades constituídas na constituição da textualidade. (2003, p.63)

A articulação pode ser feita por um articular explícito e, também, como mostra Dias (2003) pela relação da língua com a enunciação, mais especificamente, com a história de enunciações que estabelece os lugares para as palavras ocuparem em relação às outras palavras.

A relação de determinação que se dá pela articulação e pela reescrituração é, portanto, fundamental na análise que realizamos de maneira que a representamos pelo que Guimarães (2007) denomina como Domínio Semântico de Determinação (DSD), que, por sua vez, representa o que a palavra designa no texto. 


\section{Análise: Os sentidos de escravidão no Jornal "Folha da Noite"}

O jornal Folha da Noite surgiu em fevereiro de 1921, fundado por Olival Costa e Pedro Cunha. Em 1925 foi criada a Folha da Manhã, versão diurna da Folha da Noite. Posteriormente, em 1949, surge a Folha da Tarde. Em 1960, os três jornais se transformam em apenas um, sob o título de Folha de São Paulo5.

Começamos nossa pesquisa no jornal "Folha da Noite", o mais antigo. O arquivo digital começa a partir do ano de 1921. Como hipótese, esperávamos encontrar notícias que tratassem da escravidão dos negros, talvez denunciando a escravidão ilegal que possivelmente poderia ainda existir no início do século XX. Procedemos trazendo ora o texto completo, analisando os recortes com enunciados relevantes, ora apenas os recortes dos textos, pois apenas alguns enunciados eram relevantes.

A primeira notícia em que encontramos a palavra escravidão refere-se ao tratamento dado aos soldados pelos oficiais do exército.

Vejamos:

Jornal Folha da Noite- 17/03/1921

"Grave Reclamação: 0 tratamento dispensado pelos oficiais do exército aos seus inferiores"

1. Não é a primeira vez, que nos chegam ás mãos, reclamações quanto ao modo brusco, indelicado e descabível que certos officiaes dispensam aos seus subordinados.

2. Comprhendendo mal e executando peor, a sua missão de superiores, esses officiaes comettem actos, que, mesmo dentro da rígida disciplina millitar não têm razão de ser.

3. Essa attitude de alguns cria, em torno do exercito, uma atmosfera de desconfiança, temor e animosidade cujos prejuizos são faccis de avaliar.

4. Ainda agora a imprensa de todo o paíz, e nós mesmos, lastimamos a porcentagem diminuta dos sorteados que se apresentaram ás fileiras para cumprir o seu dever. As causas determinantes dessa attitude dos nossos jovens

\footnotetext{
${ }_{5}$ Dados retirados do site <http://www1.folha.uol.com.br/institucional/historia_da_ folha.shtml>. Acesso em 15 jun. 2016.

6 Procuramos manter a ortografia original em todo o corpus.
} 
v. 7 (1)

175-192

jan/jun

2017

são múltiplas e, entre elas, uma das mais poderosas é justamente essa que faz do exército, exagerando, um lugar de escravidão. São abusos que precisam ser eliminados.

5. Damos abaixo a última carta que nos chegou ás mãos, sobre as attitudes de certos superiores:"Illmo. Sr. redactor: - Rogamos a vossa exa. a fineza de chamar a atenção do ilustrado sr. General commandante desta região para o procedimento que o tenente Azurem Costa teve ontem, 15 de corrente, pela maneira, em plena rua nos chamando de burros, como se fossemos seus irmãos so porque 0 mesmo tenente mandou uma manobra errada e como nós ficassemos quietos elle poz-se a gritar "soldados burros,soldados ignorantes, Soldados burros!". E isso é facil de verificar porque lá na estação de Sant'anna, estava repleta de gente (... ilegível) mas não somos nem cachorros nem tampouco criados deste ilustre e abnegado instrutor.

Não assignamos tampouco porque sabemos que se o fizermos seremos irremediavelmente expulsos. As victimas"

Para identificarmos o que designa a escravidão nesse texto, recorremos às paráfrases, recurso analítico que possibilita que descrevamos, através de enunciados, os sentidos presentes no texto. Então temos:

1. O exército é um lugar de escravidão

Neste enunciado parafrástico retirado do parágrafo 4, escravidão determina o exército pela predicação. Escravidão também reescreve a enumeração "modo brusco, indelicado e descabido". Os enunciados "Actos que não têm razão de ser" e "procedimento de chamar de burros" reescrevem escravidão expandindo seu sentido. Representamos essas relações de sentido pelo esquema chamado Domínio Semântico de Determinação

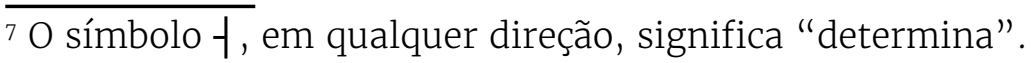


DSD 1

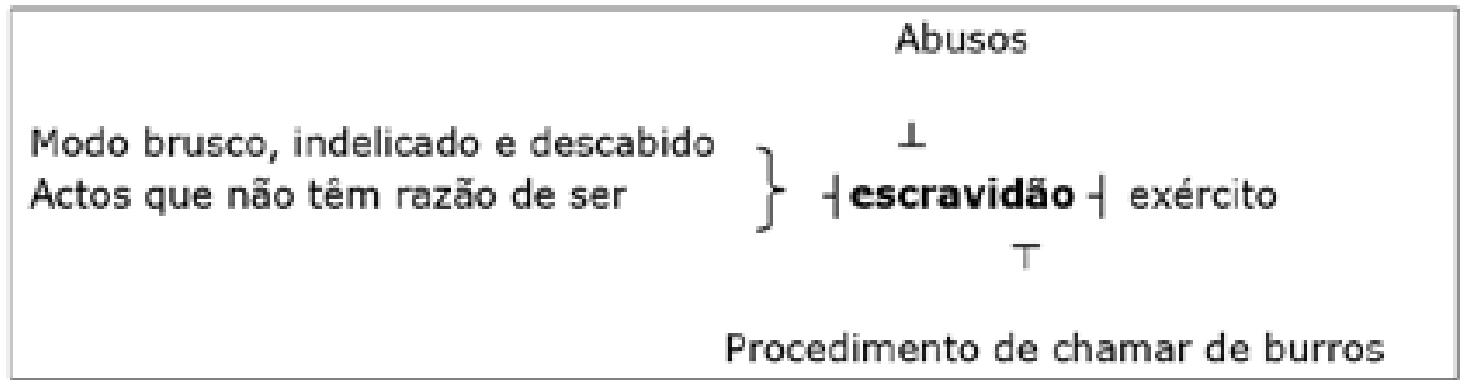

Neste acontecimento enunciativo, a cena enunciativa reconstitui outra cena enunciava pois o locutor jornalista recebe uma denúncia dos soldados do exército que relatam o que foi dito pelo locutor oficial do exército a estes soldados.

Os sentidos de escravidão que são rememorados nessa cena reconstituída na notícia se constituem do lugar enunciativo do exército e rememoram um possível modo como eram tratados os escravos no que tange apenas à violência verbal. E é essa aproximação semântica que possibilita que o locutor soldado afirme ser o exército um lugar de escravidão. Passemos ao recorte seguinte.

\title{
Folha da Noite - 21/11/1922
}

\section{Sem título, sem autor}

\begin{abstract}
"(...)De um ponto de vista estritamente regionalista, talvez a substituição do dr. Borges ( de Medeiros, chefe do Estado do Rio Grande do Sul) por um homem mais adiantado, embora dentro do mesmo systema, seria uma solução satisfactoria.

O Povo rio-grandense conhece e reconhece o absurdo das disposições da sua actual organização e deseja modifical-as. E mesmo a parte a escravidão a que esta sujeito deve ser apoiado com interesse por todos os seus irmãos de outros estados.(...)"
\end{abstract}

Vejamos os seguintes enunciados parafrásticos do segundo parágrafo:

1. A atual organização do povo rio-grandense é absurda.

2. O povo rio-grandense está sujeito à escravidão.

Daqui, podemos identificar que "sujeito à escravidão" traz o sentido de sujeição à escravidão. Nesse caso, de sujeição do povo à 
v. 7 (1)

175-192

jan/jun

2017

organização estabelecida pelo dr. Borges, chefe do estado do Rio Grande do Sul na época.

Temos então o DSD:

Absurdo da actual organização

$\perp$

Sujeição fescravidăo

Nesse texto, temos o contexto sócio-histórico-político imediato da época. O povo rio-grandense estava sujeito ao governo de Borges de Medeiros há muitos anos.

A sujeição remete aos sentidos de "dependência, subordinação, submissão". Além dessa acepção, o dicionário Michaelis ainda traz uma segunda acepção: "Característica daquele que aceita a dominação sem reagir, sem se rebelar; obediência, resignação"». Tal determinação rememora uma rede de sentidos da escravidão dos negros, ligada a discursos que consideram que eles se tornaram escravos e assim permaneceram por tantos séculos no Brasil porque não resistiam, não reagiam, eram obedientes. Esse discurso apaga completamente os mecanismos violentos que os mantinham cativos, pela utilização de instrumentos de aprisionamento, como correntes, tortura, chicotes, o tronco, pessoas para vigiá-los e persegui-los, os chamados "capitães do mato", etc.

No recorte analisado, a submissão aparece em relação ao poder político, de uma pessoa que ficou muito tempo no poder, nem sempre de ética, já que era comum a prática do voto de cabresto, por exemplo.

Passemos a outro recorte:

\section{Folha da Noite - Sábado, 12 de maio de 1923}

\section{Sem título e sem autor}

1. A folhinha da República aponta-nos amanhan o 13 de Maio, dia da libertação dos escravos ..._pretos. E o 15 de novembro da mesma folhinha anuncia-nos a data do inicio da escravatura... branca.

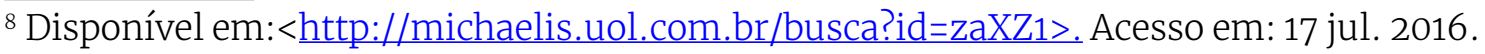


2. Apenas há uma differença aparente nas duas commemorações: uma é de pretos, outra é de brancos, mas no fundo, a escravidão passou daqueles para estes.

3. No tempo dos pretos, emquanto estes gemiam a dor irremediável do trafico e da pancadaria grossa, o branco bancava o importante, chefe de si, da sua liberdade, dos seus direitos políticos e civis e outras ornamentações mais ou menos confortaveis da vida.

4. Vao dahi, seis mezes após, 13 dias depois do Finados, meia duzia de barbados como Deodoro, Quintino e Constant resolveram patrioticamente proclamar a Republica, pondo mar em fora, o santo da devoção do sr. Cunha Bueno, Armando Prado o mais republicanos históricos, s. nl__o senhor d. Pedro II, com a mão dos brasileiros, a imperatriz Christina, que teve aquelle acto comovente de beijar o chão do Brasil no momento de embarcar no "Alageas".

5. Estavam lançados os primeiros fundamentos do novo edifício da escravidão nacional, chamada emphaticamente de Republica.

6. O positivismo fez logo das suas blagues, das quaes é ainda renascente o sr. Borges de Medeiros, que lá está no Rio Grande a escravizar o gaúcho além dos 25 annos de eito.

Veio depois a politiquice de guarda-comida, com revoluções e comidelas de todo o gosto.

7. A seguir, veio a proclamação das olygarchias federaes, estaduais, municipaes o districtaes, esta ultima invenção do sr. Olavo Egydio em S. Paulo, com Logullos, Badolatos, Dalboscos, Mollinaros, fora os meudos symetricamente asfaltados na política da cidade com ramificações por todos os ângulos do funcionalismo publico.

8. Seguindo a marcha rápida da escravidão, organisaramse as panelinhas de directorios no interior, com ligações umbellicaes nas celebres Commissões Directoras, espécie de laboratorio chimico, onde se forjam personagens desconhecidas, que saem daquela retoria para representar o pensamento publico no Congresso, nas Camaras e nos logares-mammatas de primo cartelo.

9. Por fim, isto é, nos nossos dias, temos o sr. Bernardes, com o bacalhau do estado de sitio e o sr. Washington luiz, 
v. 7 (1)

$175-192$ jan/jun 2017

\section{com o tronco da lei da imprensa.}

10. Ficou definitivamente instalada a escravatura branca.

11. Resta agora ressuscitarmos Luiz Gama, Patrocinio, Antonio Bento e outros libertadores, para promoverem a propaganda do abolicionismo dos ... brancos.

Que diabo de inclinação tem o Brasil para o escravagismo? Quando não é preto, é branco escravizado.

E o bacalhau continua a ser o santo da vida dessa gente, muito embora ele ande pela hora da morte...

Vejamos as reescriturações de escravidão:

$1^{\mathrm{o}} \S$ - Escravidão (reescritura implícita) numa relação de antonímia com liberdade (libertação dos escravos...pretos);

$3^{\circ} \S$ - escravatura branca é reescrita por escravidão; $5^{\circ} \S$ - República reescrevendo por condensação por totalização a expressão novo edifício da escravidão nacional. A escravidão determina o sentido de República;

$6^{0} \S$ - novo edifício da escravidão nacional reescrito por enumeração, por:

a escravidão do gaúcho, politiquice de guarda-comida;

proclamação das oligarquias federaes, estaduais, municipaes $e$ distritais.

a organização de panelinhas de directorios no interior";

estado de sítio;

tronco da lei da imprensa.

Nesse caso, os enumerados podem ser considerados aqui como hipônimos de escravidão;

$10^{\circ} \S$ - Escravatura branca, reescritura de escravidão, que especifica seu sentido.

$13^{\circ} \S$ - Escravagismo reescreve por substituição escravidão como um sinônimo.

Encontramos no primeiro parágrafo o sintagma libertação dos escravos ...pretos. Este sintagma traz o memorável da escravidão dos 
negros no Brasil, e de maneira implícita, escravidão está numa relação de antonímia com liberdade.

Em seguida, outra data comemorativa é rememorada, o dia 15 de novembro, dia da Proclamação da República, que fica implícita, e que, nesse acontecimento enunciativo, é significada como sendo "a data do início da escravatura ... branca".

A palavra escravatura é caracterizada pelo adjetivo "branca". No parágrafo seguinte, encontramos a palavra escravidão reescrevendo por substituição o substantivo escravatura, produzindo uma sinonímia.

Mais adiante, encontramos o seguinte enunciado:

1. Estavam lançados os primeiros fundamentos do novo edifício da escravidão nacional, chamada emphaticamente de Republica.

Nele, temos o nome República reescrevendo por condensação o que vem antes: novo edifício da escravidão nacional. A República, recentemente nascida, é significada como sendo o edifício da escravidão nacional, sendo determinada pelo sentido dessa expressão.

Os parágrafos seguintes constituem-se como uma enumeração das características que significam esse Edifício da escravidão nacional.

Assim temos o sintagma "a escravidão do gaúcho" que é um elemento de sentido que compõe esse "edifício da escravidão nacional", e que rememora a submissão ao governo de Borges de Medeiros que apareceu anteriormente.

Depois, nos parágrafos seguintes, temos: a politiquice de guarda-comida; a proclamação das oligarquias federaes, estaduais, municipaes e distritais. Em seguida temos "a organização de panelinhas de directorios no interior"; depois o estado de sítio; e, por fim, o tronco da lei da imprensa. Todas essas características enumeradas determinam o que significa o Edifício da escravidão nacional.

Depois temos um parágrafo que parece uma conclusão, expressa no enunciado:

Ficou definitivamente instalada a escravatura branca.

Nesse enunciado, "escravatura branca" especifica o sentido de escravidão e totaliza todas as reescriturações anteriores que determinam 
v. 7 (1) 175-192 jan/jun 2017 a República considerada como novo edifício da escravidão nacional.

Observamos então, nesse acontecimento enunciativo, que República significa tanto o regime de governo quanto a ausência de liberdade e castigo, sofrimento, e o que havia sido enumerado antes, mas especificamente em relação ao homem branco, de modo que é determinada pelo sentido de escravidão nacional.

E, por fim, quando o locutor levanta alguns questionamentos, reescreve escravidão por escravagismo como um sinônimo.

Podemos representar o que escravidão significa nesse texto com os seguintes domínios semânticos de determinação:

\section{DSD - Escravidão antes da Abolição}

\section{Liberdade dos brancos}

Pancadaria Grossał escravidão łpretos

T

Tráfico

DSD de escravidão no período Republicano

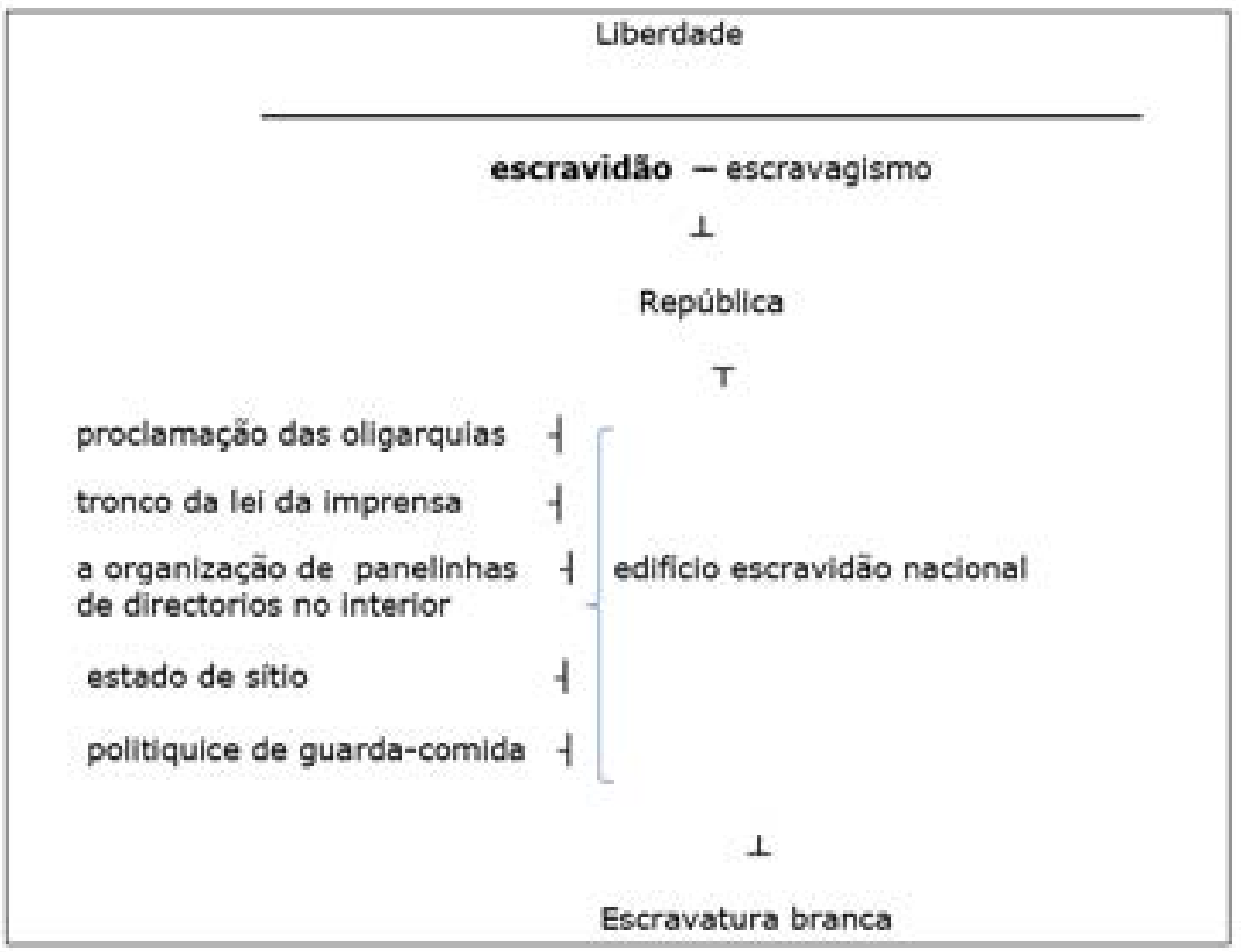


Passemos agora à última análise:

Folha da Noite - data: 07 de agosto de 1923

"Estrada de ferro Noroeste"- sem autor

"(...) Em nenhuma estrada, senão na Noroeste, andam os vencimentos em tamanho atraso. Ainda se a cooperativa fornecesse a esses homens os generos que lhes são indispensáveis, vá. Mas sendo o limite da despesa mensal apenas de $80 \$ 000$ para cada um, tal situação torna-se intolerável, inadimissivel.

Afinal, não são os funccionarios da Noroeste os unicos a soffrer com isso. Toda a população partilha de igual sorte. O commercio vendendo a longos prazos sacrifica-se enormemente. A industria, privada do estimulo, atrofia-se de modo surpreendente. E a lavoura, sem recursos, exhaurida, queda-se na imobilidade das coisas mortas.

Daqui a pouco, e a continuar o triste abandono que o governo federal a relegou, a Noroeste não terá a quem a queira servir. Escarnece-se dos funcionários, pagando-se-lhes quando isso apraz ao governo, e ainda por cima vem agora uma ordem absurda que os obriga a trabalhar aos domingos, sob pena de despedida!

Ora, uma vez que a escravidão já não existe no Brasil há quasi meio século, tratar, como se fossem burros de carga, homens prestantes e laboriosos, chega a ser um desafio vesgo á sua paciencia e espírito de resignação. (...)

Nesta notícia, o locutor-jornalista denuncia a ordem de obrigar os funcionários da Estrada de ferro Noroeste a trabalhar aos domingos. No parágrafo seguinte, afirma que a escravidão já não existe mais no Brasil o que o leva a classificar como absurdo tratar os homens como se fossem burros de carga. Temos então dois enunciados que são argumentos que orientam para a conclusão "Ainda há escravidão no Brasil", que se contrapõem à observação do locutor de que Já não existe mais escravidão no Brasil.

É, então, pela contradição que escravidão reescreve por totalização funcionários são obrigados a trabalhar aos domingos e são 
v. 7 (1)

175-192

jan/jun

2017

\section{tratados como burros de carga reescreve funcionários são obrigados a trabalhar aos domingos. Chegamos então ao seguinte DSD:}

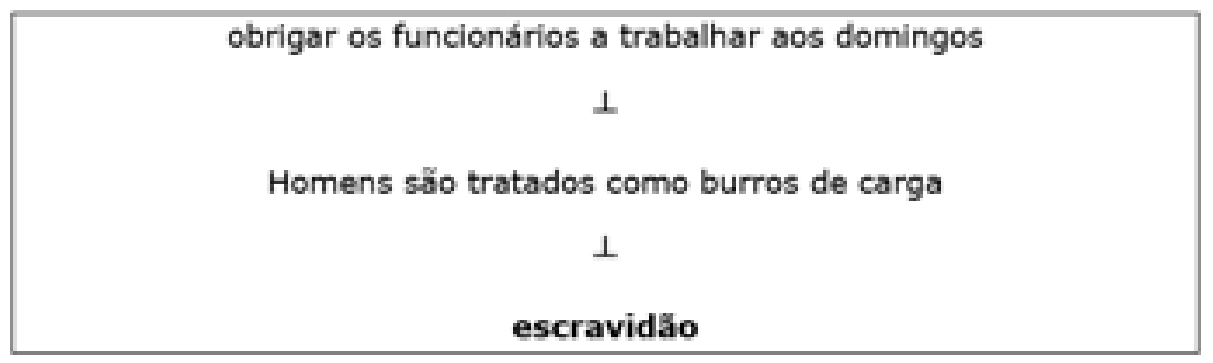

Neste acontecimento enunciativo, escravidão é designada pela relação com o excesso de trabalho. Entretanto, no início do século XX, após a abolição da escravidão, o locutor-jornalista enuncia esta escravidão de uma posição jurídica da ilegalidade da escravidão já que fora abolida, realizando então a denúncia de uma prática de trabalho escravo. Ou seja, os sentidos rememorados - trabalho aos domingos e excesso de trabalho - fazem parte da história de enunciações da palavra escravidão, mas, nesse caso, o locutor realiza uma denúncia contra esta forma de trabalho. Podemos então supor um deslizamento de sentidos entre a escravidão do passado, e a prática de escravidão no trabalho legalizado.

\section{Considerações finais}

O que designa, então, a escravidão nestes textos analisados do início do século XX, do jornal Folha da Noite?

$\mathrm{Na}$ análise do primeiro texto, escravidão aparece no contexto do exército, em que designa um modo de tratamento brusco, indelicado; o xingamento e a realização de atos sem razão de ser. Para designar a escravidão no exército, são rememorados certos sentidos da escravidão dos negros relativos à violência verbal e a atos não especificados, mas que não parecem remeter à violência física.

Depois, no contexto político, o sentido de sujeição determina escravidão. Ou seja, neste acontecimento enunciativo, é recortado apenas o sentido da submissão daquilo que pode significar a escravidão.

No artigo de 1923, fica mais claro o movimento de sentidos da palavra escravidão. A escravidão dos "pretos" designa o tráfico negreiro e a violência física, pelo sintagma "pancadaria grossa". Entretanto, a abolição da escravidão é dada como uma evidência a não ser contestada, e a escravidão vai sendo significada de outro modo. Assim, ao longo 
da análise, temos a República sendo designada como novo edifício da escravidão nacional, e este sentido vai sendo especificado e expandido ao longo do texto. Por fim, o sintagma nominal escravatura dos brancos totaliza os sentidos, reescrevendo República.

Essa divisão dos sentidos, que vemos pela designação de escravidão, revela o conflito, a disputa que acontecia no cenário político entre os opositores do governo republicano, posição da qual enuncia o locutor jornalista, e os republicanos.

A escravidão na forma do regime republicano é dos brancos, enquanto a escravidão dos negros fica no passado, já que estão livres. Mas nessa divisão do sentido de escravidão (uma dos negros e outra dos brancos), é como se o negro não fosse cidadão da República. Eram livres, mas não fazem parte da República, não têm os mesmos direitos dos cidadãos brancos por não estarem entre os "escravos" da República.

Por fim, no último artigo analisado, temos o contexto do trabalho, em que escravidão é designada como a obrigação de trabalhar aos domingos e, por comparação, trabalhar como burros de carga. E a contradição nos mostra que, apesar da afirmação do fim da escravidão, as práticas de escravidão ainda aconteciam, mas agora são tratadas como uma prática ilegal.

Observamos, então, nas designações de "escravidão" dos textos analisados, que certos sentidos de enunciações passadas são recortados no presente do acontecimento dos textos de maneira que sentidos, como o da violência física que acontecia com os escravos negros, não fazem parte dos domínios semânticos de determinação que se referem ao exército, à política e ao trabalho.

No texto de 12 maio de 1923, véspera do aniversário da abolição, vemos que República designa escravidão, uma designação inesperada, possibilitada pelo presente do acontecimento enunciativo no qual o conflito político entre republicanos e críticos do regime é significado por aquilo que a palavra designa, ocorrendo um deslizamento dos sentidos.

No último texto analisado, embora seja dito que a escravidão acabou, o locutor jornalista designa a escravidão a partir da identificação de certas práticas do trabalho legal. Vemos nessa enunciação o deslizamento de sentidos, configurando-se o que identificamos hoje como sendo trabalho análogo à escravidão.

Pelo que designa escravidão na enunciação dos textos analisados, observamos alguns modos como a escravidão acontece nesse momento da nossa história, ou seja, a escravidão continua ocorrendo de outros 
v. 7 (1)

175-192 jan/jun 2017

modos, e certos sentidos atribuídos à escravidão dos negros vão sendo deixados no passado.

\section{Referências}

GUIMARÃES, E. Semântica do Acontecimento. Campinas: Pontes, 2002. Domínio Semântico de Determinação. In: Guimarães, E. e Mollica, C. (Orgs.). A palavra: forma e sentido. Campinas: Pontes, RG Editores, 2007. Editores, 2011.

Análise de Texto: procedimentos, análises e ensino. Campinas: RG

DIAS, L. F. A sintaxe em novas dimensões. In: TOLDO, S. C. (Org.). Questões de Linguística. Universidade de Passo Fundo, UPF Editora, 2003.

Conheça a Folha de São Paulo. Disponível em: http://www1.folha.uol.com.br/ institucional/historia_da_folha.shtml Acesso em 15/07/2016.

ORLANDI, E. Análise de Discurso: princípios e procedimentos. Campinas: Pontes, 1999.

PÊCHEUX, M. Discurso: estrutura ou acontecimento. Campinas: Pontes, 1997.

Recebido em: 15 de fev. de 2017.

Aceito em: 24 de ago. de 2017. 